Tuyệt chiêu PR xà bông Cô Ba của doanh nhân Trương Văn Bền

Happy.Live

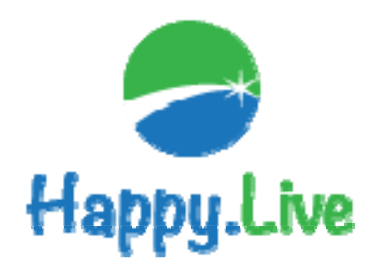

Thứ sáu, 10-03-2017 | 16:16 GMT+7

https://happy.live/tuyet-chieu-pr-xa-bong-co-ba-cua-doanh-nhan-truong-van-ben/ 


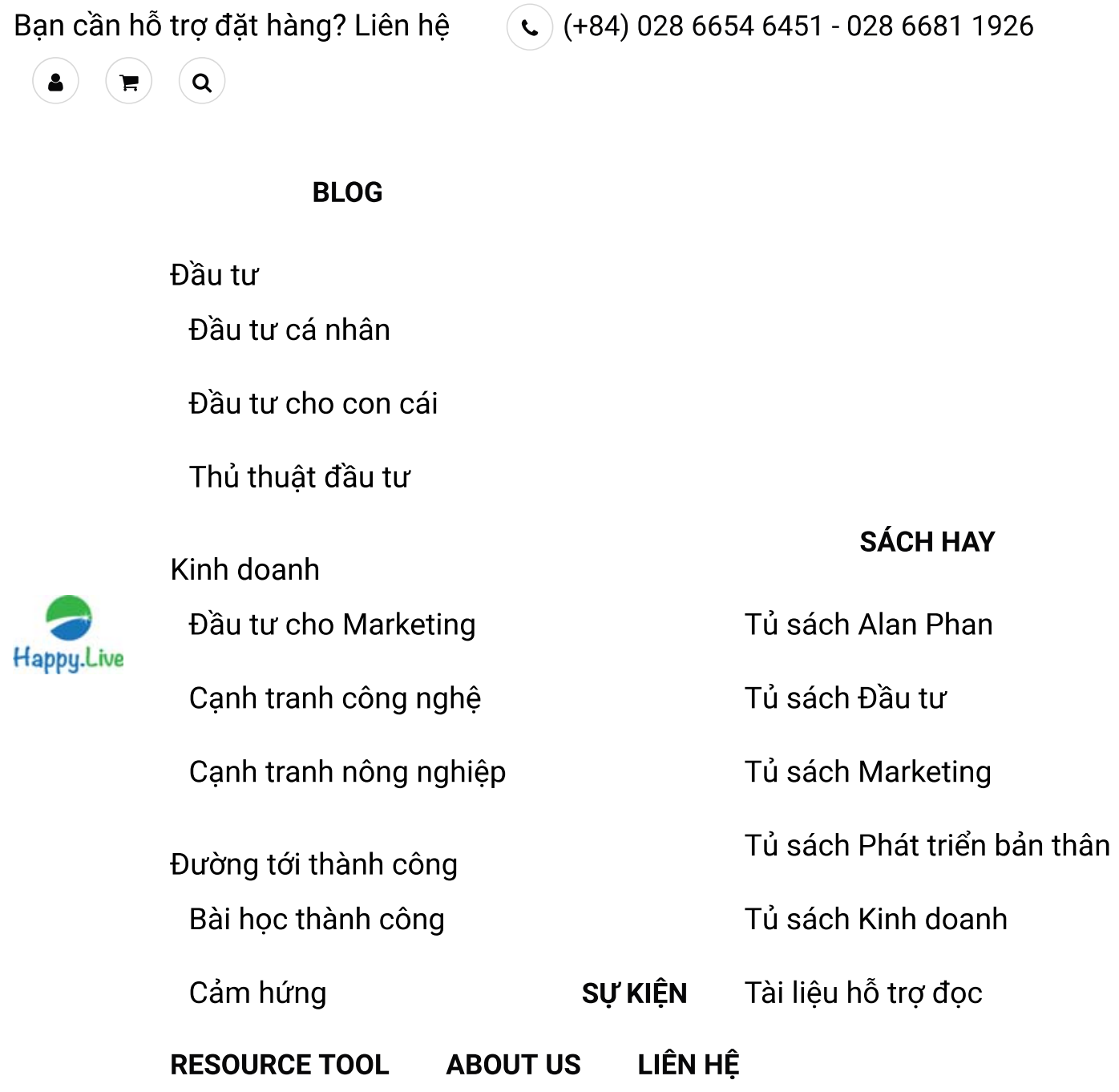

\section{Tuyệt chiêu PR xà bông Cô Ba của doanh nhân Trương Văn Bền}

Thứ sáu, 10-03-2017 / 16:16 GMT+7

Trong hồi ký của mình, ông Bền kể lại: "Tôi đang tìm kiếm tên nào kêu, dễ gọi, dễ nhớ để đặt tên cho xà bông mà chưa kiếm ra. Ngoài Bắc, phong trào cách mạng Việt Nam quốc dân đảng do Nguyễn Thái Học cầm đầu nổi lên nhiều chỗ và thất bại. Đến lúc Tây xử tử họ ở Yên Bái thì mười người như một, trước khi đút đầu vô máy chém đều bình tĩnh hô to "Việt Nam vạn tuế" gây một luồng dư luận sôi nổi ở trong nước và thế giới. Tôi chụp lấy vụ này, lấy tên Việt Nam đặt cho xà bông do người Việt sản xuất để nêu lòng ái quốc đang bùng lên: Xà bông của người Việt làm cho người Việt, người Việt yêu nước phải dùng đồ Việt Nam". 


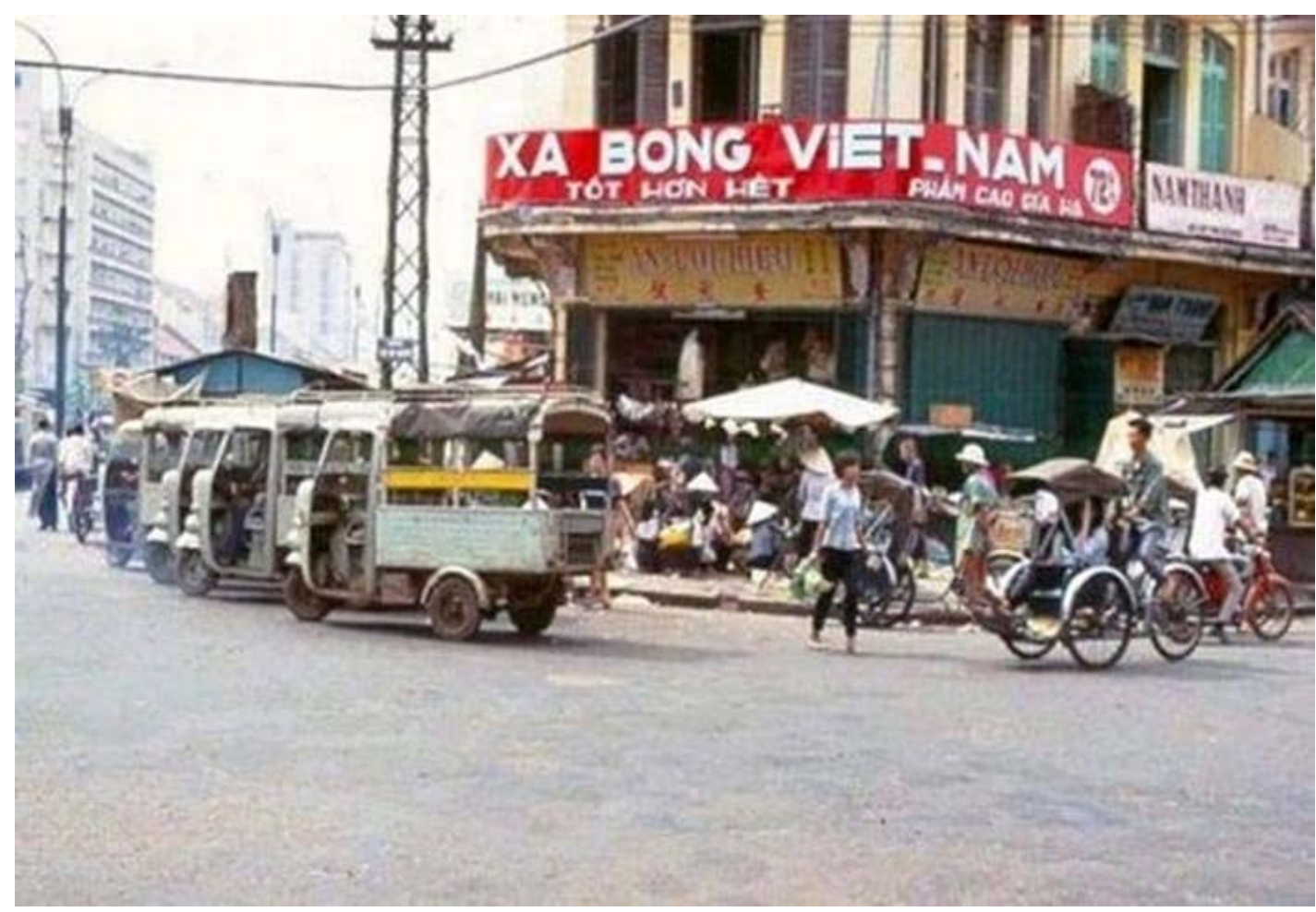

\section{Trương Văn Bền trong bối cảnh kinh tế những năm 1940}

Cho tới tận những năm đầu thập niên 40 của thế kỷ $X X$, lực lượng kinh doanh người Việt vẫn còn rất nhỏ bé. Các doanh nghiệp tư nhân Việt Nam có quy mô tương đương $1 \%$ tổng vốn đầu tư của nền kinh tế và sử dụng $9 \%$ tổng số lao động làm thuê trong công nghiệp.

Sự xuất hiện của phát xít Nhật ở Đông Dương mở ra cơ hội cho giới công thương Việt Nam. Pháp yếu thế trước Nhật, không thể tiếp tục duy trì các ưu đãi độc quyền, nhất là với những chủ thể kinh doanh "thân" Nhật. Cấm vận thương mại của phe Đồng minh với Đông Dương chặn đứt nguồn cung cấp hàng nhập khẩu và là thời cơ tốt cho sản xuất nội địa phát triển. Cộng đồng kinh doanh người Việt nổi lên chiếm địa vị cao trong xã hội thuộc địa, và phần nào tạo nên niềm tự hào, tinh thần dân tộc cho người Việt Nam.

Tại Nam Kỳ, ông Trương Văn Bền nổi danh với thương hiệu xà bông Cô Ba trên toàn xứ Đông Dương. Xuất thân trong gia đình khá giả, ông Bền nhiều lần đi Pháp nhưng chưa từng học tại một trường đào tạo kỹ nghệ hay kinh doanh chuyên nghiệp nào. Gia sản đồ sộ của ông là do công sức sáng tạo của ông làm ra, không phải thừa hưởng của gia đình, cũng không phải làm giàu nhờ ruộng đất.

Theo bảng lượng giá để đánh thuế của Phủ toàn quyền Đông Dương, thì năm 1941, ông Trương Văn Bền phải đóng số tiền lên tới 107.000 đồng Đông Dương, quy ra vàng là trên 1783 lượng. 
Buổi đầu có nhiều người hoài nghi về sự thành công của công ty Trương Văn Bền, bởi họ nghĩ rằng, với trình độ kỹ thuật học lỏm, máy móc thô sơ, thì làm sao một người Việt Nam có thể cạnh tranh nổi với người Pháp hoặc người Hoa nhiều thế lực, nhiều tiền của? Ngay những thân nhân của ông Bền lúc ấy cũng khuyên ông không nên phiêu lưu vào ngành đó, họ sợ ông tiêu phí hết những đồng vốn ít ỏi lúc ban đầu.

Nhưng mọi lời can ngăn hầu như không làm nao núng con người có đầu óc cấp tiến, thích tự lập và đương đầu với nền công nghệ mạnh gấp nhiều lần của ngoại bang lúc ấy. Ông Trương Văn Bền đã từng sống ở PhnomPenh (Campuchia), từng đi đây đó một số nơi ở ngoại quốc, nhìn thấy sự phát triển công nghiệp ở các nước, nên hơn ai hết, ông hiểu rằng, nếu quyết tâm thì không một trở lực nào có thể ngăn cản được con đường phát triển công nghệ. Ông Bền đã biết bắt đúng mạch, đánh đúng thị hiếu người tiêu dùng bằng một mặt hàng thiết yếu đó là chất giặt, tẩy.

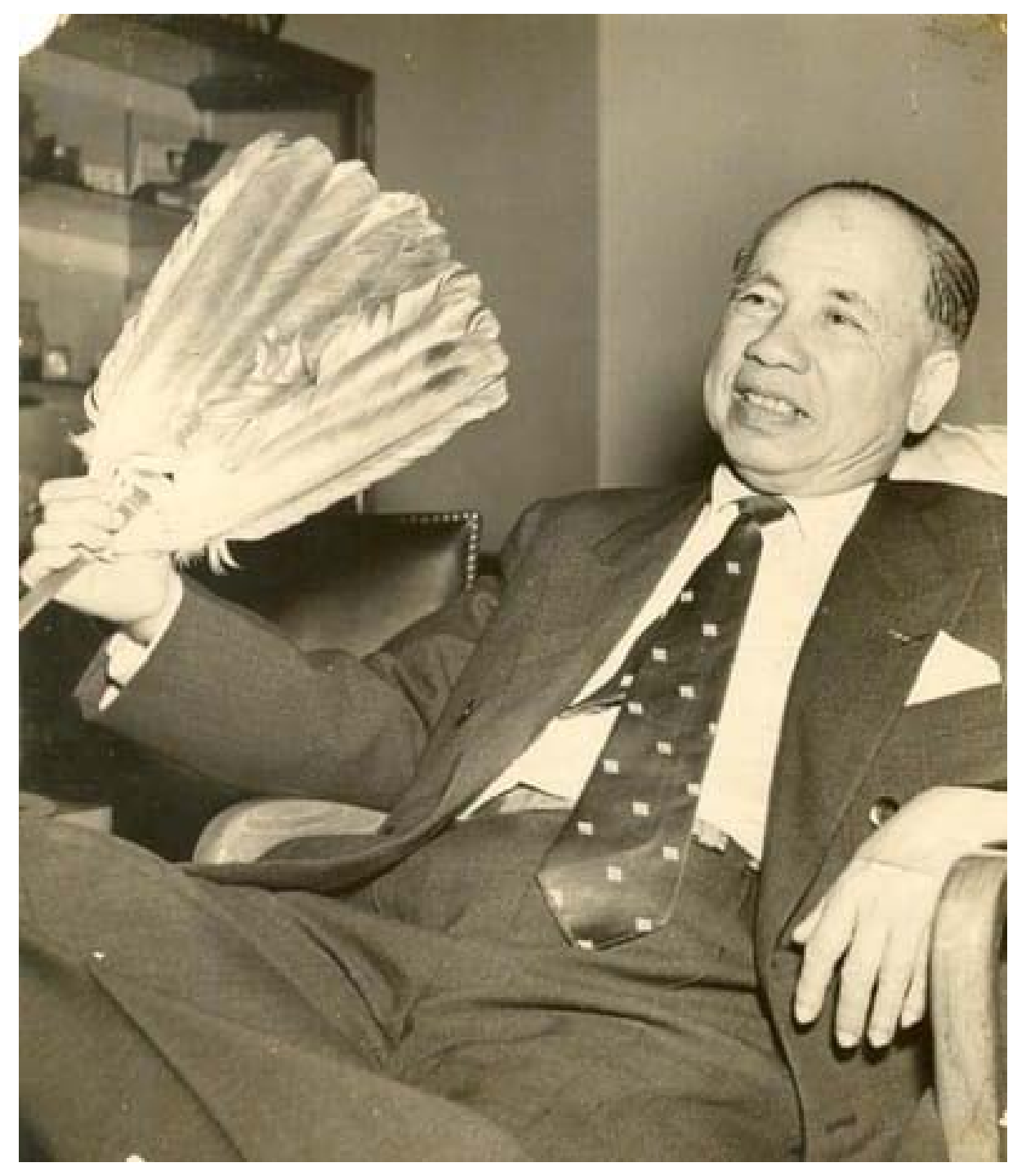

Công ty "Trương Văn Bền và các con" đã đáp ứng yêu cầu đó một cách đúng đắn. Chỉ một năm sau ngày ra đời, mặt hàng xà bông 72 phần dầu của ông Trương Văn Bền đã gần như hạ gục các sản phẩm cùng loại của nước ngoài, do giá rẻ, hợp thị hiếu người tiêu dùng và chất lượng cao. 


\section{Tại sao người Việt thường thất bại}

Trong bài báo phóng viên hỏi tại sao người Việt thường thất bại trong thương mại và kỹ nghệ. Không cần suy nghĩ lâu, ông Trương Văn Bền trả lời:

Tại người mình ưa bắt cá hai tay, ưa làm nhiều việc quá. Việc này chưa xong, họ đã xoay qua làm việc khác, thành thử không việc nào vẹn toàn. Rốt cuộc hỏng cả.

Lý do thứ nhì là do không thông thạo việc nên thất bại. Bất cứ việc gì, trước khi làm mình phải biết rõ việc ấy. Phải học, phải nghiên cứu kỹ càng mới được. Người Tây trước khi làm việc gì họ cũng học trước cả. Cho đến một việc đứng bán hàng, ta cho là tầm thường và tưởng ai ai cũng có thể làm được. Nhưng đối với họ đó là việc quan trọng cũng có sách có trường dạy hẳn hoi, dạy từ cách tiếp khách, khoe hàng làm sao cho người khách mua rồi thì còn trở lại.

Người mình có một cái rất bậy là chỉ thấy cái lợi trước mắt, chỉ cốt làm sao bán được món hàng lúc ấy mà thôi, không chịu hiểu rằng người khách thấy mình bị tiếp đãi không được như ý, hoặc bị lừa gạt mua nhầm hàng xấu, về sau không thèm trở lại nữa, vì vậy mà ế ẩm. Như tôi đây cơ sở đã vững vàng rồi mà ngày nào cũng tìm sách đọc thêm.

Năm 1918, ông Bền mở xưởng dầu thứ hai. Xưởng này sản xuất "đa hệ" từ dầu nấu ăn đến dầu dừa, dầu castor, dầu cao su và các loại dầu dùng trong kỹ nghệ. Nhận thấy tiềm năng dừa ở miền Nam rất lớn nên ông Bền đầu tư vào sản xuất dầu dừa và chính từ dầu dừa đã gợi ý cho ông đi đến bước tiếp theo là sản xuất xà bông.

Vào thời điểm đó, thị trường xà bông ở Việt Nam chủ yếu là hàng Pháp nhập vào, gọi chung là xà bông Marseille. Xà bông trong nước rất ít, chỉ có một số cơ sở sản xuất nhỏ lẻ chiếm thị phần không đáng kể, phần lớn họ sản xuất xà bông "đá" có mùi khó chịu, chỉ để rửa tay hay giặt giũ cho giới lao động, ít ai dám mạo hiểm đầu tư vào mảng xà bông thơm để tắm gội. Ông Bền đã quyết tâm đầu tư vào mảng này để cạnh tranh với hàng ngoại nhập.

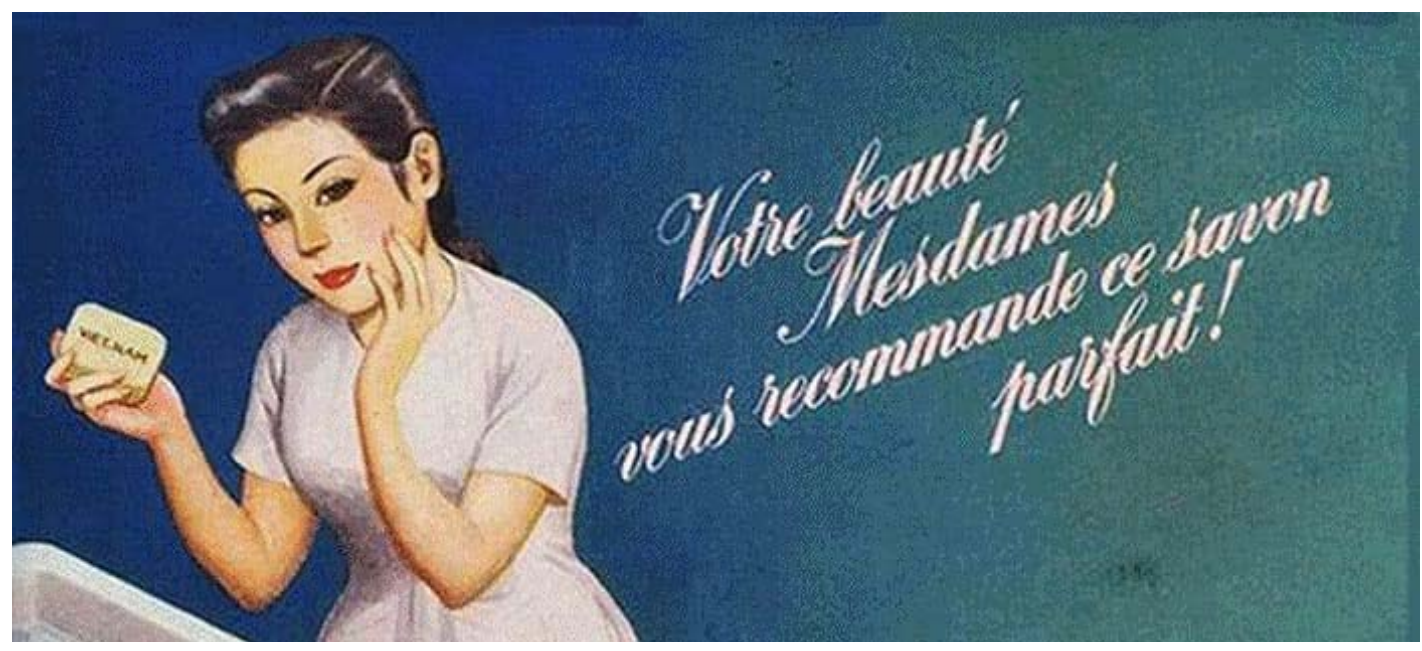




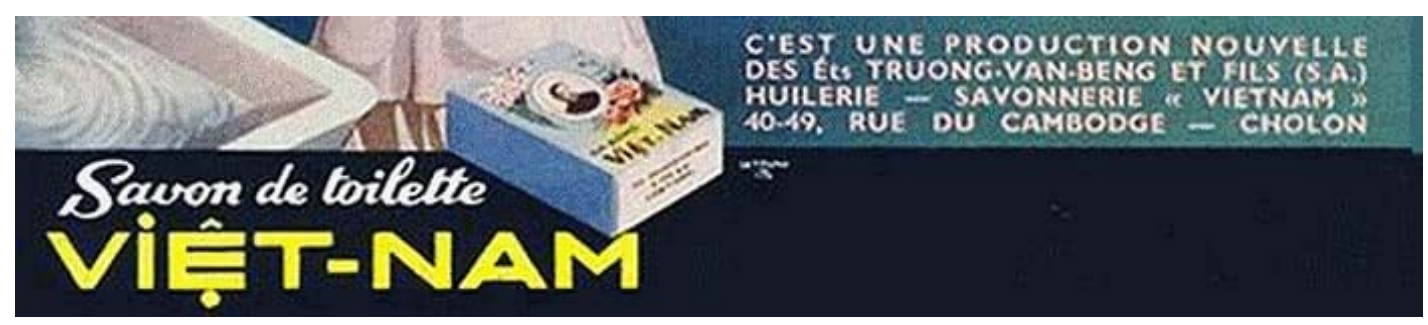

Trong hồi ký của mình, ông Bền kể lại: “Tôi đang tìm kiếm tên nào kêu, dễ gọi, dễ nhớ để đặt tên cho xà bông mà chưa kiếm ra. Ngoài Bắc, phong trào cách mạng Việt Nam quốc dân đảng do Nguyễn Thái Học cầm đầu nổi lên nhiều chỗ và thất bại. Đến lúc Tây xử tử họ ở Yên Bái thì mười người nhu một, trước khi đút đầu vô máy chém đều bình tĩnh hô to "Việt Nam vạn tuế" gây một luồng dư luận sôi nổi ở trong nước và thế giới. Tôi chụp lấy vụ này, lấy tên Việt Nam đặt cho xà bông do người Việt sản xuất để nêu lòng ái quốc đang bùng lên: Xà bông của người Việt làm cho người Việt, người Việt yêu nước phải dùng đồ Việt Nam".

\section{Làm thương hiệu từ thời còn chưa biết Marketing}

Xà bông Cô Ba có công thức rất đơn giản: $72 \%$ là dầu dừa, còn lại là xút và hương liệu. Tất nhiên ông có bí quyết để mua được loại hương liệu tạo mùi thơm lâu bền nhưng chính quảng cáo mới là lý do lớn nhất khiến nhãn hiệu xà bông này lan rộng nhanh chóng ở miền Nam lúc đó.

\section{Đánh vào lòng yêu nước}

Đầu tiên, ông vận động cho việc dùng hàng nội hóa. Các quảng cáo của ông thường ghi dòng chữ “Người Việt Nam nên xài xà bông của Việt Nam” để đánh vào lòng yêu nước, tự hào dân tộc.

Ông phủ dày đặc các quảng cáo trên áp phích, trên xe điện, xe hơi, trên áo đấu cầu thủ bóng đá, ông đưa cả vào các thể loại âm nhạc rất được ưa chuộng như ca vọng cổ, tuồng cải lương...

\section{Dẫu thành bại cũng là "mưu sự tại nhân"}

Một chiêu khác cũng được ông Bền kể lại trong hồi ký: "Tôi phải kiếm cách ép mấy hàng tạp hóa mua xà bông Việt Nam về bán. Tiệm tạp hóa hầu hết chỉ mua các món đồ thông dụng, đem lại cho họ mối lợi hằng ngày.

Tôi bèn huy động một tốp người cứ lần lượt hằng ngày đi hết các tiệm tạp hóa hỏi có xà bông Cô Ba bán không. Hễ có thì mua một, hai xu, bằng không thì đi chỗ khác, trước khi bước chân ra khỏi tiệm nói với lại một câu: "Sao không mua xà bông Việt Nam về bán? Thứ đó tốt hơn xà bông khác nhiều”. Hết người này tới người khác rồi chủ tiệm cũng phải để ý, phải hỏi lại chỗ bán xà bông Việt Nam, mua thử về bán". 


\section{Tận dụng đại dương xanh}

Khi được hỏi về bí quyết thành công, ông Bền nói: “ở xứ mình, trong giới kỹ nghệ còn trống chỗ nhiều, muốn lập kỹ nghệ nào cũng dễ lắm. Không cần phải có vốn nhiều. Vốn ít, càng tốt hơn.

Ban đầu không nên làm rình rang, đã vô ích mà còn có hại, cứ khởi sự nho nhỏ, đi lần lần từng bước. Cần nhất phải có chí nhẫn nại. Như tôi đây bị thất bại đã mấy phen, nhưng có thất bại mới có thêm kinh nghiệm. Thứ nhất là bền chí. Thứ hai là phải có sức khỏe, làm gì thì làm mỗi buổi sáng tôi cũng dậy sớm tập nửa giờ thể dục. Không có sức khỏe, hay đau ốm thì dẫu tài giỏi đến bực nào cũng thành vô dụng. Tóm lại sức khỏe, sự học hỏi, sự bền chí là những điều kiện của sự thành công”.

Nguồn: Tổng hợp và biên tập từ phunutoday, vietnamnet, Sách Kinh tế Việt Nam - Thăng trầm và đột phá (Phạm Minh Chính, Vương Quân Hoàng)

\section{CÁC BÀI VIẾT LIÊN QUAN}

1. Lực Chuyển về Dòng Tiền Đầu Tư Toàn Cầu! (cập nhật 8/2018)

2. Bạch Thái Bưởi - Vua hàng hải Việt kinh doanh vì tinh thần dân tộc

3. Trịnh Đình Kính - Ông hoàng thủy tinh xứ Đông Dương

\section{CÁC BÀI VIẾT CÙNG CHỦ ĐÈ}

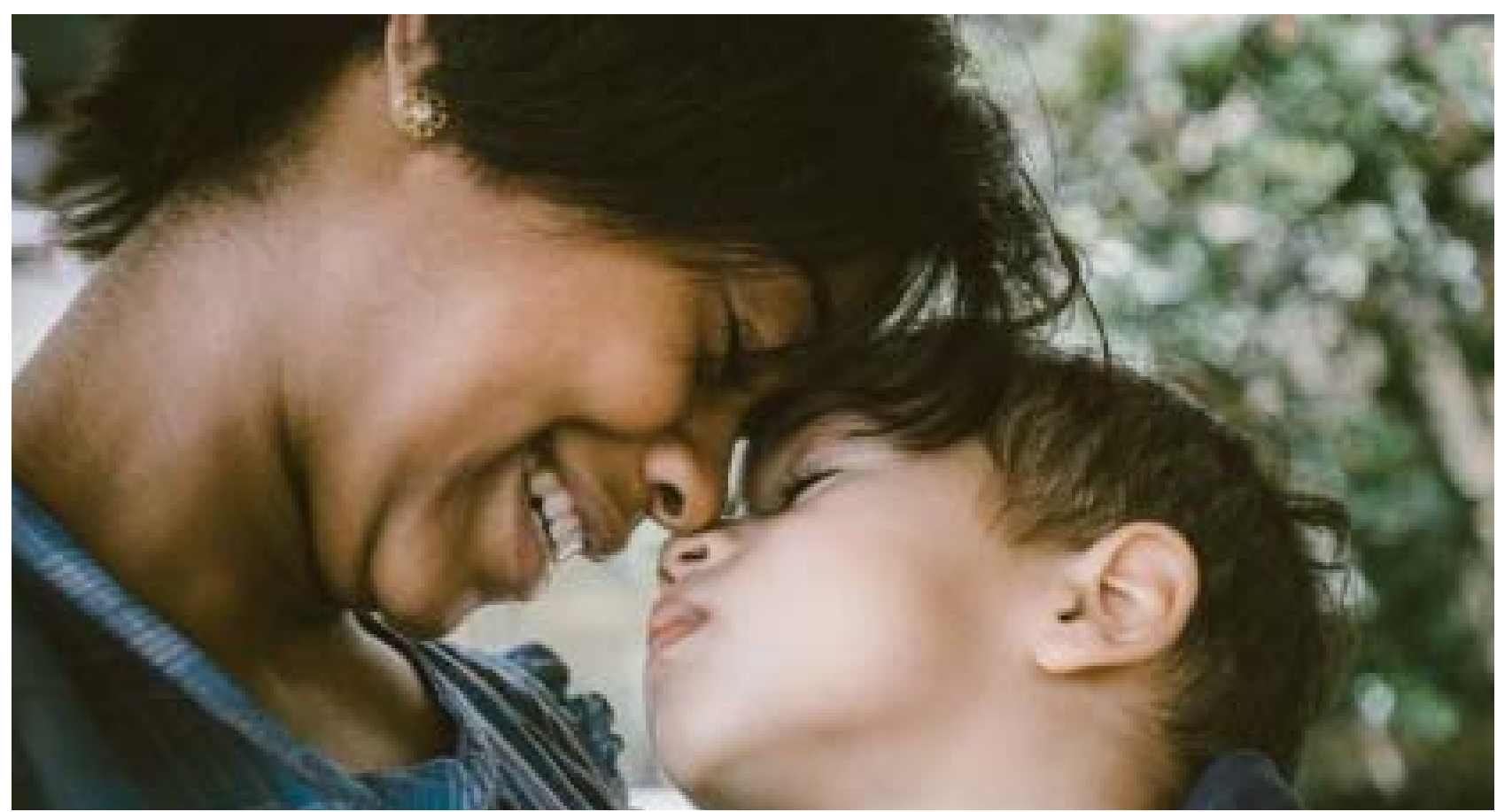




\section{Tài liệu tham khảo:}

[1] Thạch Vinh. (2014). Giai thoại về tỷ phú xà bông Trương Văn Bền. Phunutoday (22/05). https://phunutoday.vn/giai-thoai-ve-ty-phu-xa-bong-truong-van-bend15202.html

[2] Vietnamnet. (2017). Hình ảnh người đẹp bí ẩn trên thương hiệu xà bông nức tiếng một thời. Vietnamnet (27/05). https://vietnamnet.vn/vn/doi-song/chuyen-la/hinhanh-nguoi-dep-bi-an-tren-thuong-hieu-xa-bong-nuc-tieng-mot-thoi-374784.html

[3] Phạm Minh Chính, Vương Quân Hoàng. (2009). Kinh tế Việt Nam: Thăng trầm và đột phá. NXB Chính trị quốc gia, Hà Nội. 